\title{
Impact of the Ground on the Series Impedance of Overhead Power Lines
}

\author{
Anastázia Margitová ${ }^{1)}$, Michal Kolcun ${ }^{2)}$ and Martin Kanálik ${ }^{3)}$ \\ 1) 2) 3) Department of Electric Power Engineering, FEI TU of Košice, Slovak Republic \\ e-mail: ${ }^{1)}$ Anastazia.Margitova@tuke.sk,${ }^{2)}$ Michal.Kolcun@tuke.sk, ${ }^{3)}$ Martin.Kanalik@tuke.sk
}

\begin{abstract}
An overhead power line is a structure used in the electric power system to transmit electrical energy. The performance of overhead power lines depends on their parameters. There are four basic electrical parameters of power lines: resistance, inductance, capacitance, and shut conductance. The paper focuses on the calculation of the series impedance of overhead lines (resistance and inductance) by three different methods (Carson's method, Rüdenberg's method and the theory of complex penetration depth) considering the impact of the ground return path. There is also the comparison of these methods and their application on models of real power lines of different voltage levels provided in this paper.
\end{abstract}

Keywords - electrical parameters of power lines, resistance, inductance, series impedance, Carson's method, ground return, complex penetration depth.

\section{INTRODUCTION}

In standard calculations of electrical parameters of power lines there are some simplifications, such as current flows trough phase conductors are symmetric, in the case of a dual-system power line current flows in the first system are identical to current flows of the second system, mean distances between conductors are considered. The impact of the ground on the series impedance of power lines is not considered [1], [2]. The purpose of these common methods is to determine the one operating parameter (the mean inductance) which replaces the magnetic effect of all conductors of the system on the particular conductor.

Distances between conductors are different in practice, so the electrical parameters of each conductor have different values. The calculation methods presented in this article are aimed at expressing the relationships between conductors of the one system, but also between conductors of several systems. The result of the individual parameter calculation is not the one value, but the matrix of parameters. The dimensions of the matrix, rows and columns indicate the number of conductors in the system. There are the self-parameters of conductors placed on the matrix diagonal and the relations between conductors are expressed apart from the diagonal [3].

The purpose of presented methods for calculating the series impedance of power lines is to create a simple way to determine both the individual and the mutual parameters of conductors with required precision for a wide range of geometric arrangement, environment, materials, and so on. There are three basic concepts (Carson's, Rüdenberg's, and
Deri's methods) for calculating the series impedance of power lines with consideration of the impact of the ground. These methods differ from one another according to configuration of conductors and properties of the ground. All theories assume that the biggest density of the alternating current in the ground is directly below the line and quickly drops to the sides as well as to the depth. All three theories consider that the ground is a steady current conductor, which has its self-parameters, thus its series impedance is not equal to zero [3], [4].

\section{RÜDENBERG'S CONCEPTION}

The Rüdenberg's conception for calculating the self and mutual series impedance of conductors is considered to be the simplest mathematical one, based on several assumptions in [3]. This method replaces the effect of the ground on the resistance and inductance of conductors by fictitious conductors according to Fig. 1. The configuration of $n$ conductors and the one ground is replaced by $n$ real conductors and $n$ fictitious conductors. The theory considers that the currents flowing through the fictitious conductors have opposite polarity as currents flowing through the real conductors. The distance between conductors and their images is equal to $D_{\mathrm{g}}$.

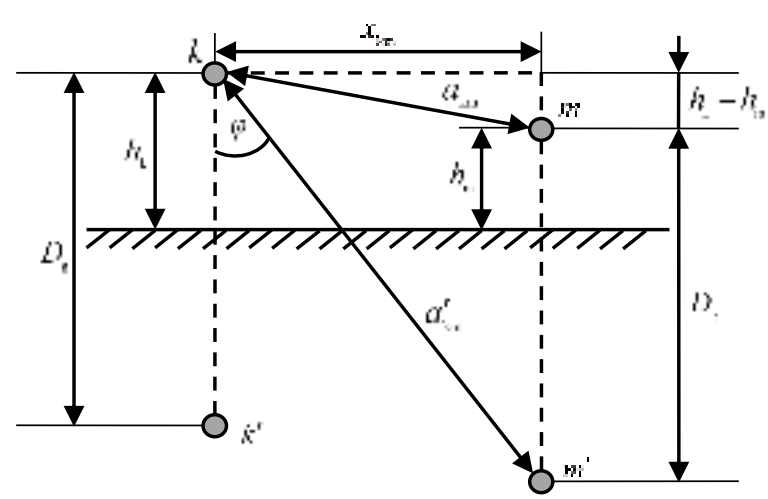

Fig. 1. Model of two conductors and their images at a distance $D_{\mathrm{g}}$.

The size of the $D_{\mathrm{g}}$ is not dependent on the height of the conductor above the ground, usually it is $h \ll D_{\mathrm{g}}$. The value $D_{\mathrm{g}}$ is given by relation [3]: 


$$
D_{\mathrm{g}}=\frac{0,178 \sqrt{10^{7} \rho}}{\sqrt{f}}(\mathrm{~m})
$$

where

$\rho \quad$ is the ground resistivity $(\Omega \mathrm{m})$,

$f \quad$ is the frequency $(\mathrm{Hz})$.

According to the Rüdenberg's theory the self impedance $\bar{Z}_{\mathrm{kk}}$ of the conductor $k$ can be determined as [3]:

$\bar{Z}_{\mathrm{kk}}=R_{\mathrm{kk}}+\mathrm{j} \omega L_{\mathrm{kk}}=R_{\mathrm{k}}+R_{\mathrm{g}}+\mathrm{j} \omega \frac{\mu_{0}}{2 \pi} \ln \frac{D_{\mathrm{g}}}{\xi_{\mathrm{k}} r_{\mathrm{k}}} \quad\left(\Omega \mathrm{m}^{-1}\right)$,

where

$R_{\mathrm{kk}} \quad$ is the self resistance of the conductor $k\left(\Omega \mathrm{m}^{-1}\right)$

$R_{\mathrm{k}} \quad$ is the AC resistance of the conductor $k$ without considering the influence of the ground according to [4] (it may include the influence of temperature, skin effect, twisting ropes, and sag) $\left(\Omega \mathrm{m}^{-1}\right)$,

$R_{\mathrm{g}} \quad$ is the ground resistance $\left(\Omega \mathrm{m}^{-1}\right)$, specified in [4],

$L_{\mathrm{kk}}$ is the self-inductance of the conductor $k$ $\left(\mathrm{Hm}^{-1}\right)$,

$\xi_{\mathrm{k}} \quad$ is the factor that represents the skin effect and magnetic properties of the conductor $k$ material $(-)$,

$r_{\mathrm{k}} \quad$ is the radius of the conductor $k(\mathrm{~m})$,

$\omega$ is the angular frequency $\left(\mathrm{s}^{-1}\right)$,

$\mu_{0}$ is the vacuum permeability $\left(\mathrm{Hm}^{-1}\right)$,

$\mu_{0}=4 \pi \cdot 10^{-7} \mathrm{Hm}^{-1}$.

Contribution to the series impedance of the conductor $k$ from the conductor $m$ and its corresponding fictitious conductor $m^{\prime}$ (the mutual series impedance $\bar{Z}_{\mathrm{km}}$ between conductors $k$ and $m$ ) is the relation [3]:

$$
\begin{gathered}
\bar{Z}_{\mathrm{km}}=R_{\mathrm{km}}+\mathrm{j} \omega L_{\mathrm{km}}=R_{\mathrm{g}}+\mathrm{j} \omega \frac{\mu_{0}}{2 \pi} \ln \frac{a_{\mathrm{km}}^{\prime}}{a_{\mathrm{km}}}\left(\Omega \mathrm{m}^{-1}\right), \\
a_{\mathrm{km}}^{\prime}=\sqrt{\left[D_{\mathrm{g}}+\left(h_{\mathrm{k}}-h_{\mathrm{m}}\right)\right]^{2}+x_{\mathrm{km}}^{2}}(\mathrm{~m}), \\
R_{\mathrm{km}}=R_{\mathrm{mk}}, L_{\mathrm{km}}=L_{\mathrm{mk}}, \bar{Z}_{\mathrm{km}}=\bar{Z}_{\mathrm{mk}}
\end{gathered}
$$

where

$R_{\mathrm{km}} \quad$ is the mutual resistance between the conductors $k$ and $m\left(\Omega \mathrm{m}^{-1}\right)$,

$L_{\mathrm{km}} \quad$ is the mutual inductance between the conductors $k$ and $m$, the contribution to the conductor $k$ inductance from the conductor $m$ and its corresponding fictitious conductor $m^{\prime}\left(\mathrm{Hm}^{-1}\right)$,

$a_{\mathrm{km}}^{\prime} \quad$ is the distance between the conductor $k$ and the image of the conductor $m(\mathrm{~m})$ according to Fig. 1,

$a_{\mathrm{km}} \quad$ is the distance between the conductor $k$ and the conductor $m(\mathrm{~m})$ according to Fig. 1, $h_{\mathrm{k}} \quad$ is the height of the conductor $k$ over the ground (m),

$h_{\mathrm{m}} \quad$ is the height of the conductor $m$ over the ground (m),

$x_{\mathrm{km}}$ is the horizontal distance between the conductors $k$ and $m(\mathrm{~m})$.

\section{FULL AND SIMPLIFIED CARSON'S METHOD}

The theory was published in 1926 and is still a standard for calculating the series impedance of power lines. Carson assumes that the ground is a uniform, flat, solid and infinite surface with the constant resistivity [5]. The method expresses the series impedance of power lines as an improper integral, which can be developed into infinite series [6] - [9]. For practical purposes, it is sufficient to consider the finite number of elements in the series. The Carson's theory includes the influence of the ground on the series impedance by adding correction factors to the equations. The derivation of these relations is based on Fig. 2.

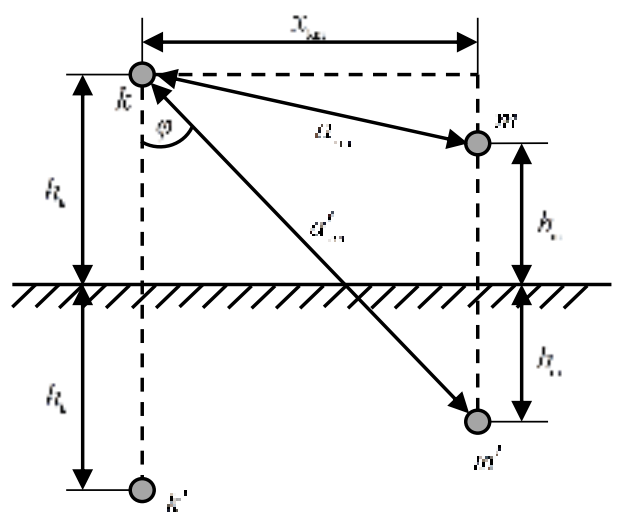

Fig. 2. Model of two conductors and their mirror images with respect to the plane of the ground.

The self resistance $R_{\mathrm{kk}}$ and self inductance $L_{\mathrm{kk}}$ of the conductor $k$ (according to Fig. 2) can be determined as [10]:

$$
\begin{aligned}
& R_{\mathrm{kk}}=R_{\mathrm{k}}+\Delta R_{\mathrm{kk}}=R_{\mathrm{k}}+4 \cdot 10^{-7} \omega P \quad\left(\Omega \mathrm{m}^{-1}\right), \\
& L_{\mathrm{kk}}=\frac{\mu_{0}}{2 \pi} \ln \left(\frac{2 h_{\mathrm{k}}}{\xi_{k} r_{\mathrm{k}}}\right)+\Delta L_{\mathrm{kk}} \quad\left(\mathrm{Hm}^{-1}\right) \\
& L_{\mathrm{kk}}=\frac{\mu_{0}}{2 \pi} \ln \left(\frac{2 h_{\mathrm{k}}}{\xi_{k} r_{\mathrm{k}}}\right)+4 \cdot 10^{-7} Q\left(\mathrm{Hm}^{-1}\right)
\end{aligned}
$$

where

$\Delta R_{\mathrm{kk}}$ is the Carson's correction factor for the conductor $k$ self resistance with respect to the ground $\left(\Omega \mathrm{m}^{-1}\right)$,

$\Delta L_{\mathrm{kk}}$ is the Carson's correction factor for the conductor $k$ self inductance with respect to the ground $\left(\mathrm{Hm}^{-1}\right)$,

$P \quad$ is the factor determining the correction factor for the resistance $\left(\Omega \mathrm{m}^{-1}\right)$, 
$Q \quad$ is the factor determining the correction factor for the inductance $\left(\mathrm{Hm}^{-1}\right)$.

For the mutual resistance $R_{\mathrm{km}}$ and inductance $L_{\mathrm{km}}$ between the conductors $k$ and $m$, the following applies [10]:

$$
\begin{aligned}
& R_{\mathrm{km}}=\Delta R_{\mathrm{km}}=4 \cdot 10^{-7} \omega P \quad\left(\Omega \mathrm{m}^{-1}\right), \\
& L_{\mathrm{km}}=\frac{\mu_{0}}{2 \pi} \ln \left(\frac{a_{\mathrm{km}}^{\prime}}{a_{\mathrm{km}}}\right)+\Delta L_{\mathrm{km}} \quad\left(\mathrm{Hm}^{-1}\right) \\
& L_{\mathrm{km}}=\frac{\mu_{0}}{2 \pi} \ln \left(\frac{a_{\mathrm{km}}^{\prime}}{a_{\mathrm{km}}}\right)+4 \cdot 10^{-7} Q \quad\left(\mathrm{Hm}^{-1}\right),
\end{aligned}
$$

where

$\Delta R_{\mathrm{km}} \quad$ is the Carson's correction factor for the mutual resistance between the conductors $k$ and $m$ with respect to the ground $\left(\Omega \mathrm{m}^{-1}\right)$,

$\Delta L_{\mathrm{km}} \quad$ is the Carson's correction factor for the mutual inductance between the conductors $k$ and $m$ with respect to the ground $\left(\mathrm{Hm}^{-1}\right)$,

$a_{\mathrm{km}}^{\prime} \quad$ is the distance between the conductor $k$ and the image of the conductor $m(\mathrm{~m})$ according to Fig. 2,

$a_{\mathrm{km}} \quad$ is the distance between the conductor $k$ and the conductor $m(\mathrm{~m})$ according to Fig. 2.

The factors $P$ and $Q$ which are used to determine correction factors for the resistance and inductance depend on the frequency ground resistivity and configuration of conductors. Reference [4] contains equations for their calculation.

Many commercial software programs use a simplified Carson's method to calculate electrical parameters of power lines with the sufficient precision. The simplified version of the Carson's equations considers only a few expressions in equations for calculating factors $P$ a $Q$. After simplification [4], [10]:

$$
\begin{gathered}
L_{\mathrm{kk}}=\frac{\mu_{0}}{2 \pi} \ln \left(\frac{658,37 \sqrt{\frac{\rho}{f}}}{\xi_{\mathrm{k}} r_{\mathrm{k}}}\right)\left(\mathrm{Hm}^{-1} ; \mathrm{Hm}^{-1}, \Omega \mathrm{m}, \mathrm{Hz},-, \mathrm{m}\right),(9) \\
L_{\mathrm{km}}=\frac{\mu_{0}}{2 \pi} \ln \left(\frac{658,37 \sqrt{\frac{\rho}{f}}}{a_{\mathrm{km}}}\right)\left(\mathrm{Hm}^{-1} ; \mathrm{Hm}^{-1}, \Omega \mathrm{m}, \mathrm{Hz}, \mathrm{m}\right) \\
R_{\mathrm{kk}}=R_{\mathrm{k}}+9,8796 \cdot 10^{-7} f(10)\left(\mathrm{m}^{-1} ; \Omega \mathrm{m}^{-1}, \mathrm{~Hz}\right) \\
R_{\mathrm{km}}=9,8796 \cdot 10^{-7} f\left(\Omega \mathrm{m}^{-1} ; \mathrm{Hz}\right)
\end{gathered}
$$

\section{THEORY OF THE COMPLEX PENETRATION DEPTH}

The concept of complex depth was developed by Dubanton in 1969 [11], Gary in 1976 [12], and Deri [8] in
1981. For the representation of the current flow, the ground is replaced by a set of conductors placed exactly under the real conductors at a complex depth $\bar{p}$ (Fig. 3) [2]. It means that distances between conductors and their images are complex numbers.

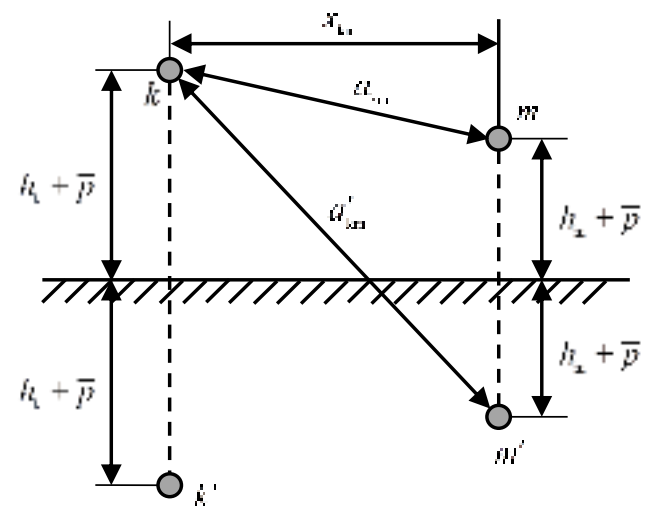

Fig. 3. Model of two conductors and their images including the complex penetration depth $\bar{p}$. [2]

The value of the complex penetration depth is given by

$$
\bar{p}=\sqrt{\frac{\rho}{\mathrm{j} \omega \mu_{0}}}(\mathrm{~m}),
$$

where $\mathrm{j}$ is the imaginary unit.

The self series impedance $\bar{Z}_{\mathrm{kk}}$ of the conductor $k$ can be determined from the equation [12]:

$$
\bar{Z}_{\mathrm{kk}}=R_{\mathrm{k}}+\mathrm{j} \omega \frac{\mu_{0}}{2 \pi} \ln \frac{2\left(h_{\mathrm{k}}+\bar{p}\right)}{\xi_{\mathrm{k}} r_{\mathrm{k}}}\left(\Omega \mathrm{m}^{-1}\right) .
$$

The expression $\mathrm{j} \omega \frac{\mu_{0}}{2 \pi} \ln \frac{2\left(h_{\mathrm{k}}+\bar{p}\right)}{\xi_{\mathrm{k}} r_{\mathrm{k}}}$ has a real and imaginary part. The real part will yield the losses in the non-ideal ground return. The result is that the conductor $k$ self resistance $R_{\mathrm{kk}}$ and inductance $L_{\mathrm{kk}}$ are described by [2]

$$
\begin{aligned}
R_{\mathrm{kk}}=R_{\mathrm{k}}+\operatorname{Re}\left\{\mathrm{j} \omega \frac{\mu_{0}}{2 \pi} \ln \frac{2\left(h_{\mathrm{k}}+\bar{p}\right)}{\xi_{\mathrm{k}} r_{\mathrm{k}}}\right\}\left(\Omega \mathrm{m}^{-1}\right), \\
L_{\mathrm{kk}}=\frac{\operatorname{Im}\left\{\mathrm{j} \omega \frac{\mu_{0}}{2 \pi} \ln \frac{2\left(h_{\mathrm{k}}+\bar{p}\right)}{\xi_{\mathrm{k}} r_{\mathrm{k}}}\right\}}{\omega}\left(\mathrm{Hm}^{-1}\right) .
\end{aligned}
$$

The mutual series impedance $\bar{Z}_{\mathrm{km}}$ between the conductors $k$ and $m$ is given by [2]:

$\bar{Z}_{\mathrm{km}}=\mathrm{j} \omega \frac{\mu_{0}}{2 \pi} \ln \frac{a_{\mathrm{km}}^{\prime}}{a_{\mathrm{km}}} \quad\left(\Omega \mathrm{m}^{-1}\right)$,

where the quantity $a_{\mathrm{km}}$ represents the distance between the conductor $k$ and the conductor $m$ according to Fig. 3. The variable $a_{\mathrm{km}}^{\prime}$ expresses the distance between the conductor 
$k$ and the image of the conductor $m$ as it is shown in Fig. 3:

$a_{\mathrm{km}}^{\prime}=\sqrt{\left(h_{\mathrm{k}}+h_{\mathrm{m}}+2 \bar{p}\right)^{2}+x_{\mathrm{km}}^{2}} \quad(\mathrm{~m})$.

The impedance $\bar{Z}_{\mathrm{km}}$ has a real part $R_{\mathrm{km}}$ and an imaginary part $\omega L_{\mathrm{km}}$ as well. The real part $R_{\mathrm{km}}$ represents a phase shift that shows up the induced voltage for including the non-ideal ground return [2], [4].

\section{IMPACT OF GROUND WIRES AND BUNDLED CONDUCTORS ON A SERIES IMPEDANCIE OF POWER LINES}

From the $220 \mathrm{kV}$ voltage level, phase conductors are made as bundles. For the high voltage (HV) transmission at 110 or $220 \mathrm{kV}$, extra-high voltage (EHV) transmission for example at 400,500, and $765 \mathrm{kV}$, ultra-high voltage (UHV) in the range of 1000 to $1600 \mathrm{kV}$ it is typical that ground wires are located at the top of the tower.

Bundled conductors are primarily employed to reduce the corona loss and radio interference. However, they have several advantages: they reduce voltage drops in conductors, improve the voltage regulation and transmission efficiency. Bundled conductor lines have higher capacitance and lower inductance than ordinary lines. As the inductance is reduced and capacitance is increased, so the surge impedance reduces and hence maximum power that can be transmitted is increased [4].

A bundle conductor is a conductor made up of two or more sub-conductors and is used as one phase conductor. It is represented by the equivalent radius and the equivalent factor representing the skin effect and magnetic properties of the conductor [4]:

$$
\begin{aligned}
r_{\mathrm{eqv}}=\sqrt[n]{r_{\mathrm{c}} d_{12} d_{13} \ldots d_{1 n}} & (\mathrm{~m}) \\
& \xi_{\mathrm{eqv}}=\sqrt[n]{\xi_{\mathrm{c}}} \quad(-),
\end{aligned}
$$

where

$n \quad$ is the number of conductors in a bundle $(-)$,

$r_{\mathrm{c}}$ is the radius of the one conductor in a bundle $(\mathrm{m})$

$d_{1 i}$ is the distance between the axis of the first conductor and the axis of the conductor $i$ in a bundle, if $i \in\langle 2 \div n\rangle(\mathrm{m})$,

$\xi_{\mathrm{c}} \quad$ is the factor that represents the skin effect and magnetic properties of one conductor in a bundle $(-)$.

As the current flow through the bundle is divided into individual conductors, the resistance of one phase per unit length is determined from the relationship [4]:

$$
R_{\text {eqv }}=\frac{R_{\mathrm{c}}}{n} \quad\left(\Omega \mathrm{m}^{-1}\right)
$$

where $R_{\mathrm{c}}$ is the resistance of one conductor in a bundle $\left(\Omega \mathrm{m}^{-1}\right)$.

When using the bundled conductors, the parameters $r_{\mathrm{k}}$, $\xi_{\mathrm{k}}, R_{\mathrm{k}}$ (of the single conductor $k$ ) in the equations for calculating the self series impedance shown above are replaced by equivalent quantities $r_{\text {ekv }}, \xi_{\text {ekv }}, R_{\text {ekv }}$.

Ground wires are bare conductors which serve to shield the line and intercept lighting stroke before it hits the current carrying conductors below. The ground wires are solidly connected to the ground at each tower in the transmission and distribution system.

Ground wires influence the parameters of power lines, their effect is included in the reduced matrix of the series impedance. The elimination of the series impedance matrix is described in [2], [4]. The reduced matrix is obtained:

$$
\left[\bar{Z}_{\text {red }}\right]=\left[\bar{Z}_{\mathrm{cc}}\right]-\left[\bar{Z}_{\mathrm{cg}} \bar{Z}_{\mathrm{gg}}\right]^{-1}\left[\bar{Z}_{\mathrm{gc}}\right]\left(\Omega \mathrm{m}^{-1}\right),
$$

where

$\left[\bar{Z}_{\mathrm{cc}}\right]$ is the square regular and symmetrical submatrix of order $m$ expressing the self and mutual series impedance of the phase conductors $\left(\Omega \mathrm{m}^{-1}\right)$,

$\left[\bar{Z}_{\mathrm{cg}}\right]$ is the rectangular submatrix of order $m \times n$ expressing the mutual series impedance between the phase conductors and ground wires $\left(\Omega \mathrm{m}^{-1}\right)$,

$\left[\bar{Z}_{\mathrm{gc}}\right]$ is the rectangular submatrix of order $n \times m$ expressing the mutual series impedance between the ground wires and phase conductors $\left(\Omega \mathrm{m}^{-1}\right)$,

$\left[\bar{Z}_{\mathrm{gg}}\right]$ is the square regular and symmetrical submatrix of order $n$ expressing the self and mutual series impedance of the ground wires $\left(\Omega \mathrm{m}^{-1}\right)$,

$m$ is the number of the phase conductors $(-)$

$n \quad$ is the number of the ground wires $(-)$.

\section{CAlculating the Series IMPEDANCE OF $22 \mathrm{KV}$, $110 \mathrm{KV}$ AND $400 \mathrm{KV}$ POWER LINES}

This chapter contains a comparison of methods for calculating the series impedance applied to power lines according to Figs. 4 to 6 . Parameters of the used conductors and properties of the ground are shown in TABLE I.

\begin{tabular}{|c|c|c|c|c|}
\hline \multicolumn{2}{|c|}{ Voltage level } & $22 \mathrm{kV}$ & $110 \mathrm{kV}$ & $400 \mathrm{kV}$ \\
\hline \multicolumn{2}{|c|}{ Rated frequency } & $50 \mathrm{~Hz}$ & $50 \mathrm{~Hz}$ & $50 \mathrm{~Hz}$ \\
\hline \multirow{2}{*}{$\begin{array}{l}\text { Conductor } \\
\text { type }\end{array}$} & $\begin{array}{c}\text { Phase } \\
\text { conductor }\end{array}$ & 95AlFe6 & $185 \mathrm{AlFe} 6$ & $350 \mathrm{AlFe} 6$ \\
\hline & $\begin{array}{c}\text { Ground } \\
\text { wire }\end{array}$ & - & $185 \mathrm{AlFe} 3$ & $185 \mathrm{AlFe} 3$ \\
\hline \multicolumn{2}{|c|}{ Ground resistivity } & $150 \Omega \mathrm{m}$ & $150 \Omega \mathrm{m}$ & $150 \Omega \mathrm{m}$ \\
\hline
\end{tabular}

TABLE I.

PARAMETERS OF CONDUCTORS USED FOR POWER LINES ACCORDING TO FIGS. 4, 5, 6 AND PROPERTIES OF THE GROUND 
The calculated parameters are given in ohms per kilometer. The frequency and resistivity of the ground are considered the same for each power line. Dimensions of electric towers and configuration of the phase conductors and ground wires in Figs. 4 to 6 are expressed in millimeters. In the case of the conductor resistance, the skin effect, temperature, rope twisting and even the sag are not considered.

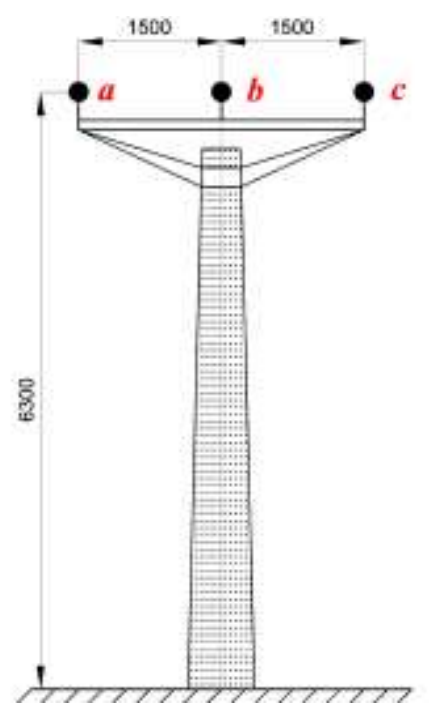

Fig. 4. Configuration of a single-circuit three-phase $22 \mathrm{kV}$ power line.

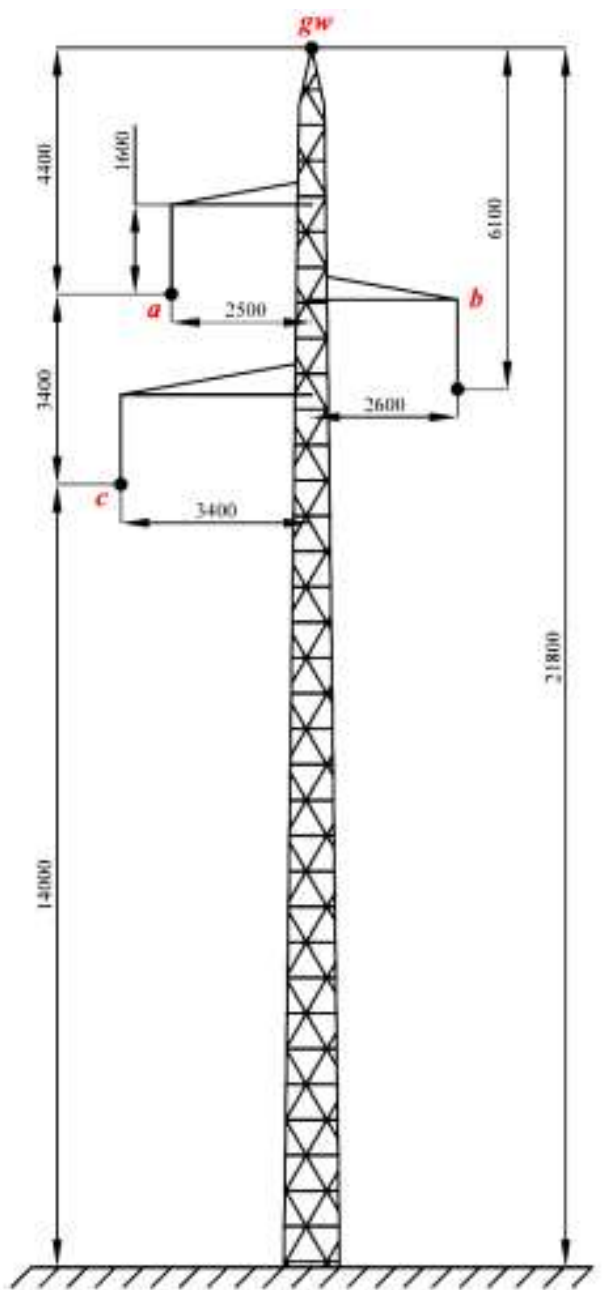

Fig. 5. Configuration of a single-circuit three-phase $110 \mathrm{kV}$ power line.

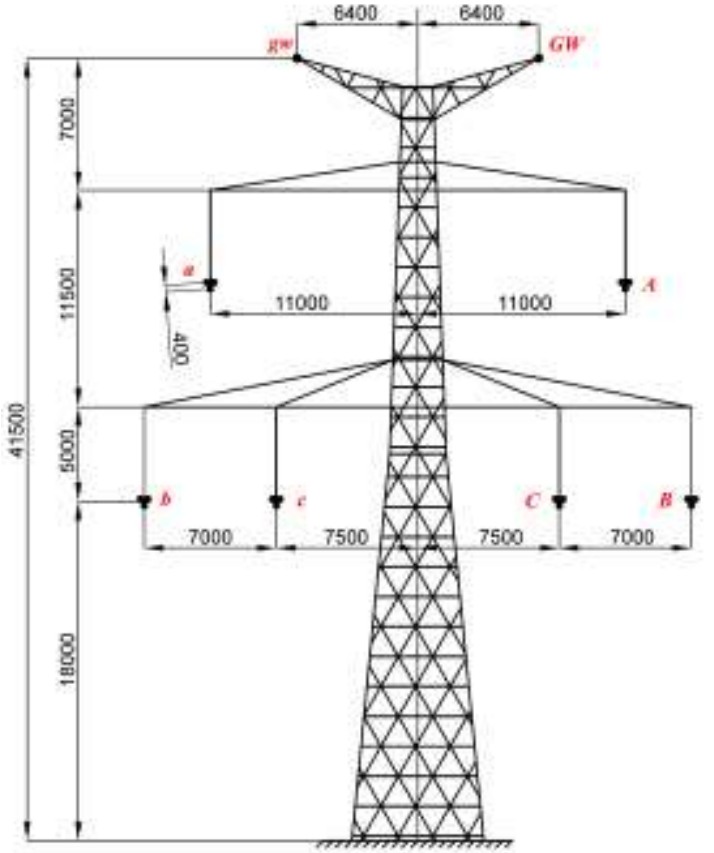

Fig. 6. Configuration of a double-circuit three-phase $400 \mathrm{kV}$ power line.

Applying the Carson's method to the model of the power line according to Fig. 6, for the self and mutual inductance in a matrix form applies (values are given in $\mathrm{mH} / \mathrm{km}$ ):

$$
\begin{aligned}
& {\left[L_{\text {Carson }}\right]=\left[\begin{array}{ll}
{\left[L_{\mathrm{cc}}\right]} & {\left[L_{\mathrm{cg}}\right]} \\
{\left[L_{\mathrm{gc}}\right]} & {\left[L_{\mathrm{gg}}\right]}
\end{array}\right]}
\end{aligned}
$$

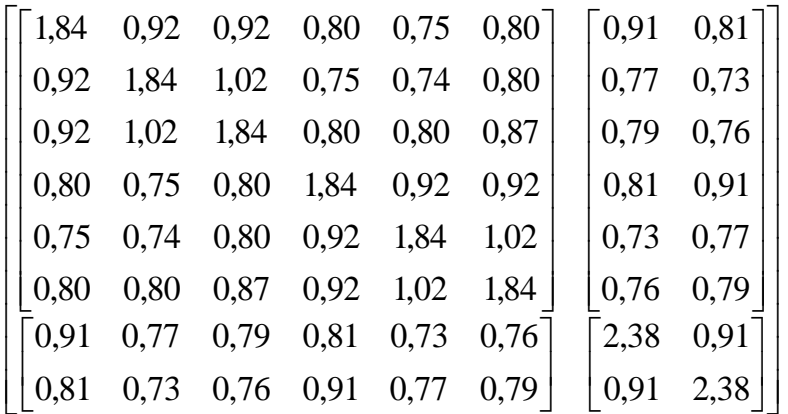

Elements in the diagonal represent the self inductance of each conductor. Values out of the diagonal express the mutual inductance between conductors. The matrix includes self parameters of the phase conductors and ground wires, also relations between these conductors. By eliminating ground wires, the reduced matrix of the phase conductors is obtained, which includes the influence of the ground wires on phase parameters of the power line:

$$
\begin{aligned}
& \begin{array}{llllll}
a & b & c & A & B & C
\end{array} \\
& \boldsymbol{a}\left[\begin{array}{llllll}
1,39 & 0,53 & 0,52 & 0,35 & 0,36 & 0,40
\end{array}\right] \\
& \begin{array}{llllllll}
\boldsymbol{b} & 0,53 & 1,50 & 0,67 & 0,36 & 0,40 & 0,44
\end{array} \\
& {\left[L_{\text {red }}\right]=\begin{array}{c|lllllll}
\boldsymbol{c} & 0,52 & 0,67 & 1,48 & 0,40 & 0,44 & 0,51 \\
\boldsymbol{A} & 0,35 & 0,36 & 0,40 & 1,39 & 0,53 & 0,52
\end{array}} \\
& \begin{array}{lllllll}
\boldsymbol{B} & 0,36 & 0,40 & 0,44 & 0,53 & 1,50 & 0,67
\end{array} \\
& \text { C }\left[\begin{array}{lllllll}
0,40 & 0,44 & 0,51 & 0,52 & 0,67 & 1,48
\end{array}\right]
\end{aligned}
$$


In Figs. 7 to 12 it is shown a graphical comparison of results given by the above mentioned methods for calculating the series impedance of the $110 \mathrm{kV}$ power line.

In the case of the self inductance (see Figs. 7 and 8), according to the method of the complex depth, the highest values were achieved. The lowest self inductance was determined by the Rüdenberg's theory. If the influence of the ground wire is not considered, the values of the self inductance determined by Rüdenberg, Deri and Carson are approximately identical (see Fig. 7).

However, the existence of the ground wire at the top of the tower reduces the conductor self inductance (see Fig. 8). With considering the elimination of the ground wire, the conductor $a$ self inductance is the smallest value because the distance between the conductor $a$ and the ground wire is smaller than the distance between the conductors $b$ and $c$ from the ground wire. On the other hand, the inductance of the conductor $c$ is the largest because it is farthest from the ground wire.

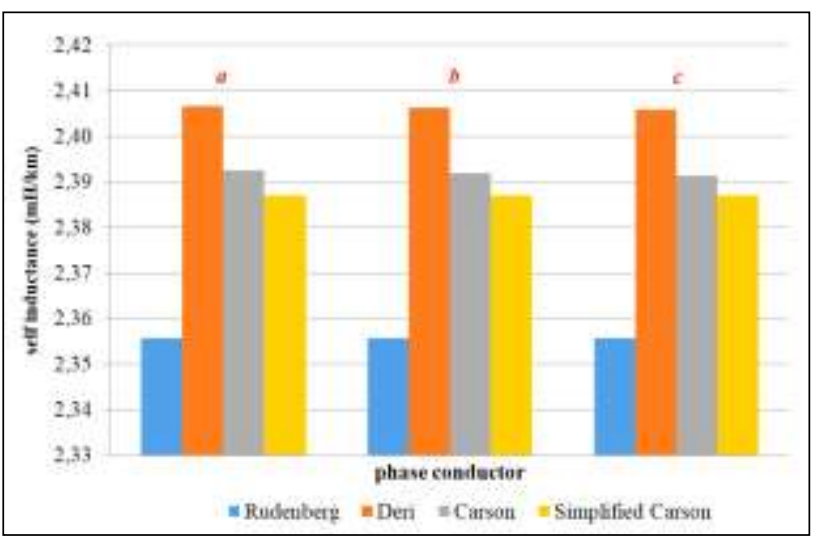

Fig. 7. Comparison of the self inductance of the $110 \mathrm{kV}$ power line determined by different methods (without considering the influence of the ground wire).

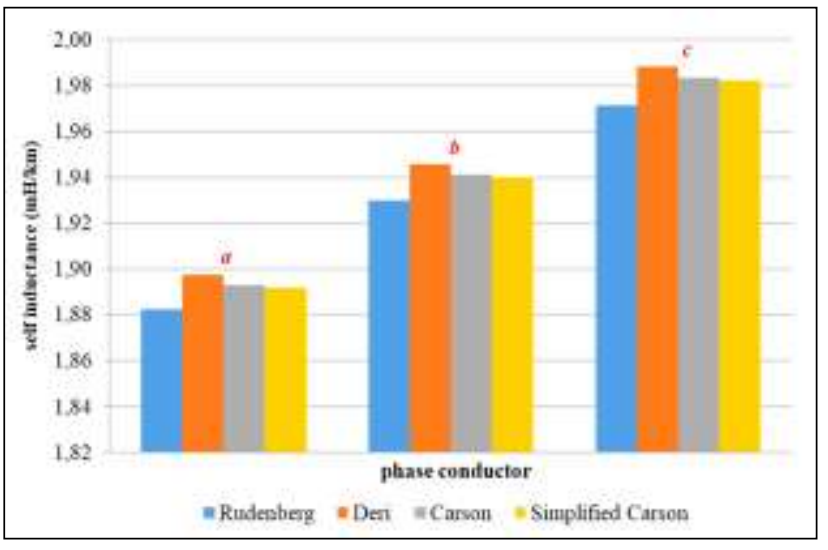

Fig. 8. Comparison of the self inductance of the $110 \mathrm{kV}$ power line determined by different methods (with considering the influence of the ground wire).

Figures 9 and 10 describe the mutual inductance between the conductors $a-b$ and $a-c$. It is clear from Fig. 9 the larger distance between conductors affects the lower mutual inductance between them. Just as in the case of the self inductance, the impact of the ground wire reduces the mutual inductance between the phase conductors.

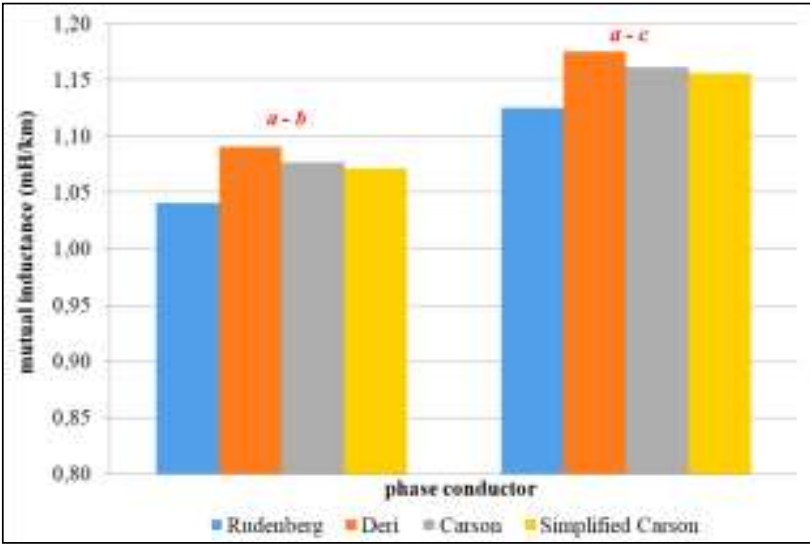

Fig. 9. Comparison of the mutual inductance of the $110 \mathrm{kV}$ power line determined by different methods (without considering the influence of the ground wire).

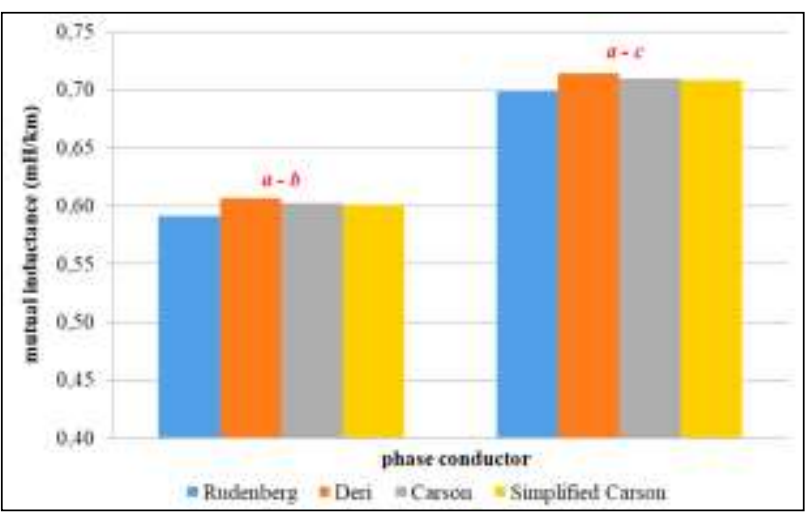

Fig. 10. Comparison of the mutual inductance of the $110 \mathrm{kV}$ power line determined by different methods (with considering the influence of the ground wire).

The highest values of the self resistance were calculated according to the Rüdenberg's theory and simplified Carson's method, but they are constant values. Only the resistance of the ground (in the case of the Rüdenberg's theory) and frequency (in terms of the simplified Carson's method), in addition to the AC resistance of the conductor, is included in the calculation of its self resistance. For the full Carson's and Deri's methods, the self resistance of the conductors $a, b$ and $c$ differs from each other due to dependence on the configuration of the conductors. The bigger height of the conductor above the ground, the less its self resistance (Fig. 11).

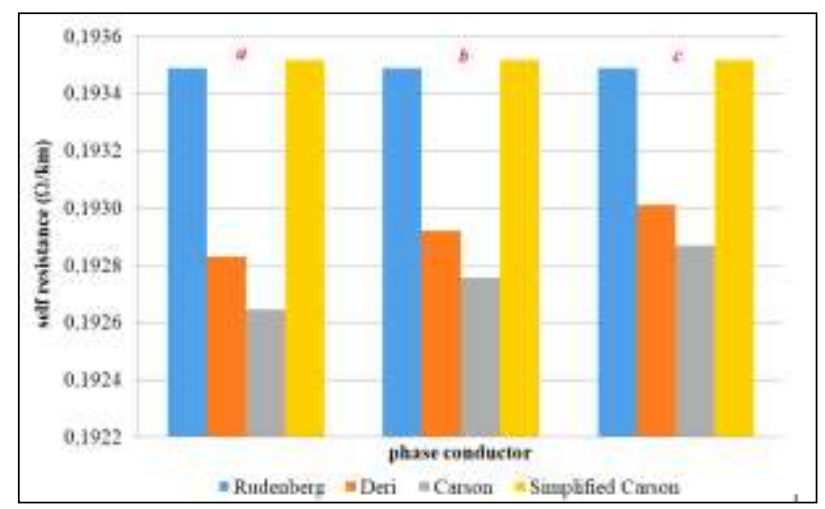

Fig. 11. Comparison of the self resistance of the $110 \mathrm{kV}$ power line determined by different methods (with considering the influence of the ground wire). 
In the case of the mutual resistance of the $110 \mathrm{kV}$ power line, the same facts apply as in the case of its self resistance (Fig. 12). The existence of the ground wire reduces the self and mutual resistance of the phase conductors, too. In the case of the $22 \mathrm{kV}$ power line, values of the self resistance and inductance for each conductor are the same because the phase conductors $a, b, c$ are placed at the same height.

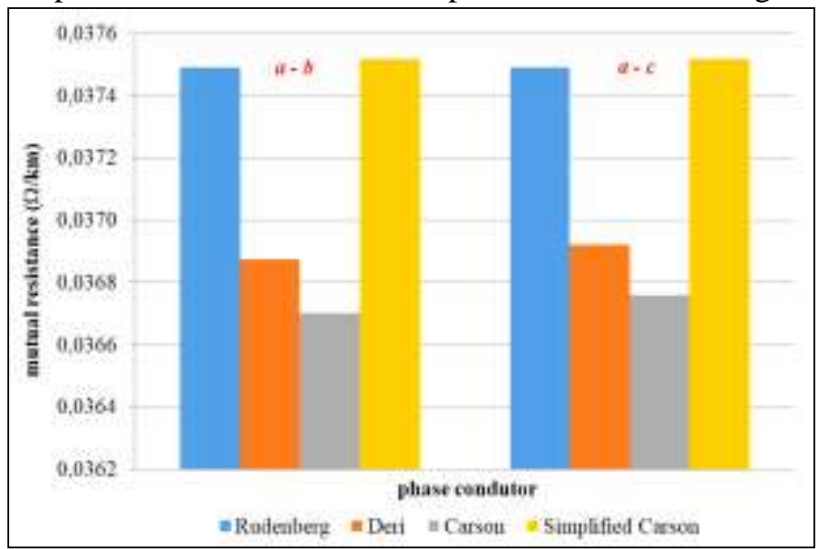

Fig. 12. Comparison of the mutual resistance of the $110 \mathrm{kV}$ power line determined by different methods (with considering the influence of the ground wire).

The Carson's theory is considered to be the most accurate method for calculating the series impedance of the above-mentioned methods, since it develops the calculation into infinite series. TABLE II lists the deviations of the remaining methods from the Carson's conception for the power lines discussed in this article (with considering ground wires).

TABLE II.

COMPARISON OF THE RÜDENBERG'S, SIMPLIFIED CARSON'S AND DERI'S CONCEPTION WITH THE FULL CARSON'S METHOD FOR THE

CAlCUlating PARAMETERS OF $22 \mathrm{KV}, 110 \mathrm{KV}$ AND $400 \mathrm{KV}$ POWER LINES

\begin{tabular}{|c|c|c|c|}
\hline $\begin{array}{c}\text { Voltage } \\
\text { level }\end{array}$ & $\begin{array}{l}\text { Calculation } \\
\text { method }\end{array}$ & $\begin{array}{c}\text { Maximum } \\
\text { resistance } \\
\text { deviation }(\%)\end{array}$ & $\begin{array}{c}\text { Maximum } \\
\text { inductance } \\
\text { deviation }(\%)\end{array}$ \\
\hline \multirow{3}{*}{$22 \mathrm{kV}$} & $\begin{array}{l}\text { Rüdenberg's } \\
\text { conception }\end{array}$ & 1,21 & $-1,36$ \\
\hline & $\begin{array}{l}\text { Theory of the } \\
\text { complex depth }\end{array}$ & 0,28 & 1,26 \\
\hline & $\begin{array}{l}\text { Simplified } \\
\text { Carson's } \\
\text { method }\end{array}$ & 1,31 & $-0,08$ \\
\hline \multirow{3}{*}{$110 \mathrm{kV}$} & $\begin{array}{l}\text { Rüdenberg's } \\
\text { conception }\end{array}$ & 2,15 & $-0,56$ \\
\hline & $\begin{array}{l}\text { Theory of the } \\
\text { complex depth }\end{array}$ & 0,48 & 0,78 \\
\hline & $\begin{array}{c}\text { Simplified } \\
\text { Carson's } \\
\text { method } \\
\end{array}$ & 2,23 & $-0,05$ \\
\hline \multirow{3}{*}{$400 \mathrm{kV}$} & $\begin{array}{l}\text { Rüdenberg's } \\
\text { conception }\end{array}$ & 2,64 & $-0,60$ \\
\hline & $\begin{array}{l}\text { Theory of the } \\
\text { complex depth }\end{array}$ & 0,59 & 1,14 \\
\hline & $\begin{array}{l}\text { Simplified } \\
\text { Carson's } \\
\text { method }\end{array}$ & 2,70 & 0,03 \\
\hline
\end{tabular}

In terms of the inductance, comparable results with the Carson's theory were achieved using its simplified form, where the maximum percentage deviation was $0,03 \%$ (for the $400 \mathrm{kV}$ power line). In the case of the resistance, the most accurate results were achieved by applying the Deri's conception (the maximum deviation $0,28 \%$ for the $22 \mathrm{kV}$ power line). Great differences compared to the Carson's method were obtained by calculation according to the theory of Rüdenberg and simplified Carson, the maximum percent deviation was over $1,2 \%$.

By comparing the results for different voltage levels, the most accurate resistance values were obtained for the 22 $\mathrm{kV}$ line, at least accurate for the $400 \mathrm{kV}$ line. The smallest inductance deviation achieved by the Deri's and Rüdenberg's methods was determined for the $110 \mathrm{kV}$ line. For the Carson's simplified calculation, the smallest deviation value was reached for the $400 \mathrm{kV}$ line application.

The analysis of the various constructions and voltage levels of the three power lines shows that the four methods for calculating the series impedance of conductors produce comparable results.

\section{CONCLUSION}

The concepts for calculating the series impedance discussed in this article are considered with the influence of the imperfectly conductive path of the ground both on the resistance and inductance. Each theory divides the resistance and inductance of a conductor into self and mutual, and adds to equations the corrections of different shapes that characterize parameters of the ground.

The Carson's method as the only one gives an analytically complete solution that is expressed by improper integrals developed into infinite series. The influence of the ground on the resistance and inductance is expressed by the correction factors $\Delta R_{\mathrm{kk}}, \Delta R_{\mathrm{km}}, \Delta L_{\mathrm{kk}}$, $\Delta L_{\mathrm{km}}$, which are dependent on the frequency, ground resistivity and configuration of power lines (see Chapter III). The disadvantage is that this method represents difficult and time-consuming calculations.

The Deri's model represents an approximation of the Carson's theory, it is much easier, sufficiently precise and comparable to the Carson's solution. Distances between conductors and their images are represented by complex numbers (inclusion of the complex penetration depth $\bar{p}$, see Chapter IV). As a result, the series impedance can be presented in a simple algebraic shape and easier to process by computers.

The Rüdenberg's method considers the distance between the conductor and its image $D_{\mathrm{g}}$, which is constant, depends only on the frequency and resistivity of the ground. The distance $D_{\mathrm{g}}$ is much larger than the perpendicular distance of the conductor from the plane of the ground (see Chapter II). 


\section{REFERENCES}

[1] M. Hodinka, Š. Fecko, and F. Němeček, Přenos a rozvod elektrické energie, Praha: Nakladatelství technické literatury, 1989.

[2] H. Wayne Beaty, Handbook of Electric Power Calculations, The McGraw-Hill Companies, 2000.

[3] L. Reiss, K. Malý, Z. Pavlíček, and F. Němeček, Teoretická elektroenergetika I, $2^{\text {nd }}$ ed., Bratislava: Alfa, 1997.

[4] A. Margitová, Výpočet elektrických parametrov silových vedení. Bachelor thesis. Košice: Technická univerzita v Košiciach, FEI, 2015.

[5] J. R. Carson, "Wave Propagation in overhead wires with ground return,” Bell System Technical Journal, vol. 5, pp. 539-554, 1926. https://doi.org/10.1002/j.1538-7305.1926.tb00122.x

[6] T. Theodoulidis, "On the Closed-Form Expression of Carson's Integral," Periodica Polytechnica Electrical Engineering and Computer Science, vol. 59, pp. 26-29, 2015. https://doi.org/10.3311/PPee.7894

[7] A. Ramirez and F. Uribe, "A broad range algorithm for the evaluation of Carson's integral," IEEE Transactions on Power Delivery, vol. 22, pp. 1188-1193, 2007.

https://doi.org/10.1109/TPWRD.2007.893610

[8] A. Deri, G. Tevan, A. Semlyen, and A. Castanheira, "The complex ground return plane. A simplified model for homogeneous and multilayer earth return," IEEE Transactions on Power Delivery, vol. PAS100, pp. 3686-3693, 1981.

https://doi.org/10.1109/TPAS.1981.317011

[9] T. Noda, “A double logarithmic approximation of Carson's ground return impedance," IEEE Transactions on Power Delivery, vol. 21, pp. 472-479, 2005. https://doi.org/10.1109/TPWRD.2005.852307

[10] R. Horton, W. G. Sunderman, R. F. Arritt and R. C. Dugan, „Effect of line modeling methods on neutral-to-earth voltage analysis of multi-grounded distribution feeders," 2011 IEEE/PES Power Systems Conference and Exposition, Phoenix, AZ, 2011, pp. 1-6. https://doi.org/10.1109/PSCE.2011.5772574

[11]C. Dubanton, "Calcul Approché des Paramètres Primaires et Secondaires d'Une Ligne de Transport, Valeurs Homopolaires," EDF Bulletin de la Direction des Études et Recherches, Série BRéseaux Électriques Matériels Électriques, vol. 1, pp. 53-62, 1969.

[12] C. Gari, "Approche complète de la propagation multifilaire en haute fréquence par utilisation des matrices complexes," EDF Bulletin de la Direction des Études et Recherches, Série B-Réseaux Électriques Matériels Électriques, pp. 5-20, 1976. 